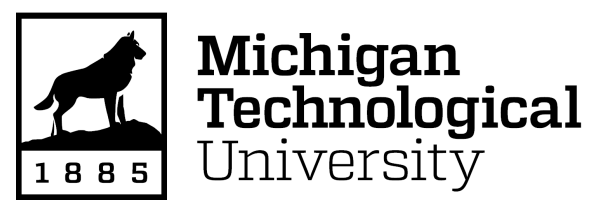

Michigan Technological University Digital Commons @ Michigan Tech

$11-27-2012$

\title{
Hygroscopic growth and CCN activity of HULIS from different environments
}

Thomas B. Kristensen

University of Copenhagen, Copenhagen

Heike Wex

Leibniz Institute for Tropospheric Research

Bettina Nekat

Leibniz Institute for Tropospheric Research

Jacob K. Nøjgaard

Aarhus University

Dominik van Pinxteren

Leibniz Institute for Tropospheric Research

See next page for additional authors

Follow this and additional works at: https://digitalcommons.mtu.edu/chemistry-fp

Part of the Chemistry Commons

\section{Recommended Citation}

Kristensen, T. B., Wex, H., Nekat, B., Nøjgaard, J. K., van Pinxteren, D., Lowenthal, D. H., Mazzoleni, L., Dieckmann, K., Koch, C. B., Mentel, T. F., Herrmann, H., \& Hallar, A. G. (2012). Hygroscopic growth and CCN activity of HULIS from different environments. Journal of Geophysical Research, 117(D22).

http://dx.doi.org/10.1029/2012JD018249

Retrieved from: https://digitalcommons.mtu.edu/chemistry-fp/11

Follow this and additional works at: https://digitalcommons.mtu.edu/chemistry-fp

Part of the Chemistry Commons 


\section{Authors}

Thomas B. Kristensen, Heike Wex, Bettina Nekat, Jacob K. Nøjgaard, Dominik van Pinxteren, Douglas H. Lowenthal, Lynn Mazzoleni, Katrin Dieckmann, Christian Bender Koch, Thomas F. Mentel, Hartmut Herrmann, and A. Gannet Hallar 


\title{
Hygroscopic growth and CCN activity of HULIS from different environments
}

\author{
Thomas B. Kristensen, ${ }^{1}$ Heike Wex, ${ }^{2}$ Bettina Nekat, ${ }^{2}$ Jacob K. Nøjgaard, ${ }^{3}$ \\ Dominik van Pinxteren, ${ }^{2}$ Douglas H. Lowenthal, ${ }^{4}$ Lynn R. Mazzoleni, ${ }^{5}$ \\ Katrin Dieckmann, ${ }^{2}$ Christian Bender Koch, ${ }^{1}$ Thomas F. Mentel, ${ }^{6}$ \\ Hartmut Herrmann, ${ }^{2}$ A. Gannet Hallar, ${ }^{7}$ Frank Stratmann, ${ }^{2}$ and Merete Bilde ${ }^{1}$ \\ Received 21 June 2012; revised 21 September 2012; accepted 29 September 2012; published 28 November 2012.
}

[1] Humic-like substances (HULIS) constitute a significant fraction of aerosol particles in different environments. Studies of the role of HULIS in hygroscopic growth and cloud condensation nuclei $(\mathrm{CCN})$ activity of aerosol particles are scarce, and results differ significantly. In this work the hygroscopic growth and $\mathrm{CCN}$ activity of water extracts (WE) and HULIS extracted from particulate matter (PM) collected at a polluted urban site (Copenhagen, Denmark), a rural site (Melpitz, Germany) and the remote site Storm Peak Laboratory (Colorado, USA) were investigated. Measurements of inorganic ions, elemental carbon, organic carbon and water soluble organic carbon (WSOC) within the PM confirmed that the sources of aerosol particles most likely differed for the three samples. The hygroscopic properties of the filtered WE were characterized by hygroscopicity parameters for subsaturated conditions $\left(\kappa_{G F}\right)$ of $0.25,0.41$ and 0.22 , and for supersaturated conditions $\kappa_{C C N}$ were $0.23,0.29$ and 0.22 respectively for the urban, rural and remote WE samples. The measured hygroscopic growth and CCN activity were almost identical for the three HULIS samples and could be well represented by $\kappa_{G F}=0.07$ and $\kappa_{C C N}=0.08-0.10$ respectively. Small amounts of inorganic ions were present in the HULIS samples so the actual values for pure HULIS are expected to be slightly lower $\left(\kappa_{G F}{ }^{*}=0.04-0.06\right.$ and $\left.\kappa_{C C N}{ }^{*}=0.07-0.08\right)$. The HULIS samples are thus less hygroscopic compared to most previous studies. To aid direct comparison of hygroscopic properties of HULIS from different studies, we recommend that the fraction of inorganic species in the HULIS samples always is measured and reported.

Citation: Kristensen, T. B., et al. (2012), Hygroscopic growth and CCN activity of HULIS from different environments, J. Geophys. Res., 117, D22203, doi:10.1029/2012JD018249.

\section{Introduction}

[2] A significant fraction of atmospheric aerosol particles consists of organic compounds [Jimenez et al., 2009]. A group of relatively large organic molecules are humic-like

\footnotetext{
${ }^{1}$ Department of Chemistry, University of Copenhagen, Copenhagen, Denmark.

${ }^{2}$ Leibniz Institute for Tropospheric Research, Leipzig, Germany.

${ }^{3}$ Department of Environmental Science, Aarhus University, Roskilde, Denmark.

${ }^{4}$ Desert Research Institute, Reno, Nevada, USA.

${ }^{5}$ Department of Chemistry, Michigan Technological University, Houghton, Michigan, USA.

${ }^{6}$ Institute for Energy and Climate Research: Troposphere, Research Center Jülich GmbH, Jülich, Germany.

${ }^{7}$ Storm Peak Laboratory, Desert Research Institute, Steamboat Springs, Colorado, USA.

Corresponding author: T. B. Kristensen, Department of Chemistry, University of Copenhagen, Universitetsparken 5, DK-2100 Copenhagen, Denmark. (thomas@chem.ku.dk)

(C2012. American Geophysical Union. All Rights Reserved. 0148-0227/12/2012JD018249
}

substances (HULIS). HULIS have been detected in marine environments [Cavalli et al., 2004; Feczko et al., 2007; Krivácsy et al., 2008], urban polluted environments [Salma et al., 2006; Krivácsy et al., 2008], rural environments [Kiss et al., 2005], sites at high altitudes [Krivácsy et al., 2001; Feczko et al., 2007] and in cloud droplets and fog [Krivácsy et al., 2000; Feng and Möller, 2004]. Since HULIS are ubiquitous in aerosol particles in different environments, several significant sources of atmospheric HULIS would be expected. Among suggested sources and formation processes are marine emissions [Cini et al., 1996; Calace et al., 2001; Cavalli et al., 2004], biomass burning [Mayol-Bracero et al., 2002; Dinar et al., 2006a; Lin et al., 2010a], oxidation of soot [Decesari et al., 2002], processes in cloud droplets [Hoffer et al., 2004; Altieri et al., 2008], and various processes leading to formation of secondary organic aerosol particles containing HULIS [Gelencsér et al., 2002; Kalberer et al., 2004]. Furthermore, it has been shown that the HULIS precursors differ in urban and remote environments [Salma et al., 2010].

[3] HULIS are polyacidic and relatively large compounds, but there is no exact definition of HULIS. Thus HULIS are 


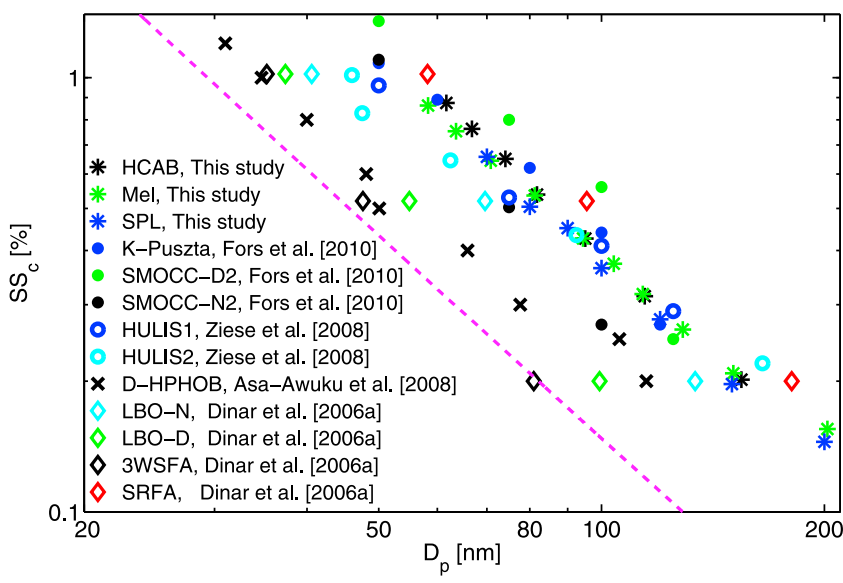

Figure 1. CCN activities of atmospheric HULIS samples as reported in the literature, together with values obtained in this study. For comparison SRFA is included, and the dashed line gives the theoretical values for ammonium sulfate. For details about the studies and samples see Table 1.

in principle defined by the applied extraction protocol. A number of different extraction protocols have been used for HULIS extraction from particulate matter (PM) [Havers et al., 1998; Varga et al., 2001; Limbeck et al., 2005; Dinar et al., 2006a], and it has been demonstrated that application of different extraction protocols leads to different yields of HULIS [Baduel et al., 2009]. This complicates comparisons of different studies of HULIS. In most studies of the hygroscopic growth and cloud condensation nuclei (CCN) activity of HULIS, the one-step extraction protocol introduced by Varga et al. [2001] was applied. There is evidence for the presence of several organic compounds in the extract, that are not polyacidic [Samy et al., 2010]. However, Lin et al. [2010b] showed that sugars and organic acids with small molecular mass, to a large extent do not end up in the HULIS extract. The organic compounds isolated by application of the one-step protocol introduced by Varga et al. [2001] will be referred to as HULIS in this study, which is in accordance with the terminology in a number of previous studies [Kiss et al., 2005; Ziese et al., 2008; Fors et al., 2010; Salma et al., 2010].

[4] HULIS are suspected to play an important part in the direct and indirect climate effects of aerosol particles. It has been shown that HULIS efficiently lower the surface tension of water solutions [Kiss et al., 2005; Salma et al., 2006; Taraniuk et al., 2007]. Some studies of the CCN activity of water soluble HULIS from different environments have been performed. Figure 1 shows the CCN activities of HULIS extracted from atmospheric samples. The reported CCN activities of HULIS in the literature are rather scattered. Details of the studies are summarized in Table 1, where the included $\kappa$ values $\left(\kappa_{C C N}\right)$ were inferred from least squares fit to the data depicted in Figure 1 . The $\kappa_{C C N}$ ranges from 0.05 to 0.34 , but if $\kappa$ values for individual data points are considered then the range is from 0.04 to 0.64 . The surface tension of water has been applied in all calculations of $\kappa$ values in this study.

[5] In the study by Dinar et al. [2006a] HULIS were extracted from three different PM samples applying an extraction protocol for fulvic acid similar to the one used by the International Humic Substances Society (IHSS). They found that the CCN activity of HULIS is relatively high,

Table 1. An Overview of Studies of Hygroscopic Growth and CCN Activity of Atmospheric HULIS Aerosol Particles ${ }^{\mathrm{a}}$

\begin{tabular}{|c|c|c|c|c|c|c|c|c|}
\hline Reference & Sample & Site & Environment & Season & PM & $G F_{90}$ & $G F_{95}$ & $\kappa_{C C N}$ \\
\hline \multirow[t]{4}{*}{ Gysel et al. [2004] } & KP010112-ISOM & K-puszta & rural & winter & $\mathrm{PM}_{1.5}$ & 1.08 & - & - \\
\hline & KP010126-ISOM & K-puszta & rural & winter & $\mathrm{PM}_{1.5}$ & 1.11 & - & - \\
\hline & KP010726-ISOM & $\mathrm{K}$-puszta & rural & summer & $\mathrm{PM}_{1.5}$ & 1.16 & $1.27^{\mathrm{b}}$ & - \\
\hline & KP010818-ISOM & K-puszta & rural & summer & $\mathrm{PM}_{1.5}$ & 1.17 & 1.30 & - \\
\hline Dinar et al. $[2006 \mathrm{a}]^{\mathrm{c}}$ & LBO-night & Tel Aviv & biomass burning & spring & $\mathrm{PM}_{10}$ & 1.18 & $1.27^{\mathrm{b}}$ & 0.18 \\
\hline \multirow[t]{3}{*}{ and Dinar et al. [2007] } & LBO-day & Tel Aviv & biomass burning & spring & $\mathrm{PM}_{10}$ & 1.24 & $1.36^{\mathrm{b}}$ & 0.26 \\
\hline & $3 \mathrm{WSFA}$ & Tel Aviv & urban & summer & $\mathrm{PM}_{10}$ & 1.47 & $1.59^{\mathrm{b}}$ & 0.34 \\
\hline & SRFA & Suwannee River & reference & - & - & 1.13 & $1.18^{\mathrm{b}}$ & 0.06 \\
\hline \multirow[t]{2}{*}{ Ziese et al. [2008] } & HULIS $^{\mathrm{d}}$ & Budapest & urban & spring & $\mathrm{PM}_{2.5}$ & 1.17 & 1.33 & 0.11 \\
\hline & HULIS2 & Budapest & urban & summer & $\mathrm{PM}_{2.5}$ & 1.05 & 1.17 & 0.14 \\
\hline Asa-Awuku et al. $[2008]^{\mathrm{e}}$ & D-HPHOB & Augusta, GA & biomass burning & spring $^{\mathrm{f}}$ & $\mathrm{PM}_{2.5}$ & - & - & 0.33 \\
\hline \multirow[t]{8}{*}{ Fors et al. [2010] } & K-puszta, winter & K-puszta & rural & winter & $\mathrm{PM}_{1.5}$ & 1.05 & 1.11 & 0.08 \\
\hline & K-puszta, summer & K-puszta & rural & summer & $\mathrm{PM}_{1.5}$ & 1.11 & 1.16 & - \\
\hline & SMOCC,D1 & Rondônia & biomass burning & autumn & $\mathrm{PM}_{2.5}$ & 1.06 & - & - \\
\hline & SMOCC,N1 & Rondônia & biomass burning & autumn & $\mathrm{PM}_{2.5}$ & 1.06 & - & - \\
\hline & SMOCC,D2 & Rondônia & biomass burning & autumn & $\mathrm{PM}_{2.5}$ & - & - & 0.05 \\
\hline & SMOCC,N2 & Rondônia & biomass burning & autumn & $\mathrm{PM}_{2.5}$ & - & - & 0.10 \\
\hline & SMOCC,D3 & Rondônia & biomass burning & autumn & $\mathrm{PM}_{2.5}$ & 1.11 & - & - \\
\hline & SMOCC,N3 & Rondônia & biomass burning & autumn & $\mathrm{PM}_{2.5}$ & 1.05 & - & - \\
\hline \multirow[t]{4}{*}{ This study } & HCAB & Copenhagen & urban & summer & $\mathrm{PM}_{10}$ & - & $1.14^{\mathrm{g}}$ & 0.08 \\
\hline & Mel & Melpitz & rural & winter & $\mathrm{PM}_{2.5}$ & - & $1.19^{\mathrm{g}}$ & 0.09 \\
\hline & SPL & Storm Peak Lab & remote & summer & $\mathrm{PM}_{2.5}$ & - & $1.09^{\mathrm{g}}$ & 0.10 \\
\hline & SRFA & Suwannee River & reference & - & - & - & $1.05^{\mathrm{g}}$ & 0.06 \\
\hline
\end{tabular}

${ }^{\mathrm{a}}$ The one step extraction protocol introduced by Varga et al. [2001] was applied if nothing else is noted under reference. The $\kappa_{C C N}$ values where calculated from least squares fit to the results depicted in Figure 1 assuming $\sigma=0.072 \mathrm{~N} / \mathrm{m}$.

${ }^{\mathrm{b}}$ Reported extrapolated value.

${ }^{\mathrm{c}}$ An extraction protocol similar to the one used by IHSS for fulvic acid was applied.

${ }^{\mathrm{d}}$ Results for the same sample was also reported by Wex et al. [2007].

${ }^{\mathrm{e}}$ The one step protocol introduced by Varga et al. [2001] was used on the hydrophobic fraction of the water soluble PM.

${ }^{\mathrm{f}} \mathrm{PM}$ collected for $\sim 1$ day at two different prescribed biomass burning events were pooled.

${ }^{\mathrm{g}}$ Results based on a refractive index of 1.63 for HULIS. 
particularly when extracted from urban PM. They also concluded that the CCN activity of HULIS originating from biomass burning PM increases with the aging of the aerosol. Asa-Awuku et al. [2008] collected PM from a prescribed biomass burning event, and the protocol introduced by Varga et al. [2001] was applied to the hydrophobic fraction of the PM. They report a relatively high CCN activity of HULIS and a low concentration of inorganic anions in the HULIS sample. Ziese et al. [2008] reported the CCN activity of urban HULIS samples collected in Budapest during spring and summer. The same protocol was also used for extraction of HULIS from K-puszta rural site and from Rondônia, Amazonia [Fors et al., 2010]. Those samples exhibited lower CCN activity compared to the results discussed above. The sample from Amazonia was considered to be dominated by biomass burning, and the samples from Budapest were considered to be dominated by urban pollution. Thus different HULIS samples seem to have quite different $\mathrm{CCN}$ activities.

[6] There are only few studies of hygroscopic growth of HULIS particles and the reported hygroscopicities differ significantly. The reported growth factors at a relative humidity $(R H)$ of $90 \%\left(G F_{90}\right)$ range from 1.05 to 1.17 for HULIS from rural K-puszta [Gysel et al., 2004; Fors et al., 2010]. $G F_{90}$ ranges from 1.05 to 1.47 for HULIS originating from polluted urban PM [Dinar et al., 2007; Ziese et al., 2008] and $G F_{90}$ ranges from 1.05 to 1.24 for HULIS originating from biomass burning PM [Dinar et al., 2007; Fors et al., 2010]. The reported $G F_{90}$ are included in Table 1 together with $G F_{95}$ when available. From the reported results of hygroscopic growth and $\mathrm{CCN}$ activity it is not obvious whether the CCN activity and hygroscopic growth of the isolated HULIS mainly are influenced by differences in chemical composition due to different formation processes and sources of HULIS, aerosol ageing or the chosen extraction protocol. To establish a foundation to investigate how the hygroscopic growth and $\mathrm{CCN}$ activity may depend on the sources and environment the HULIS originates from, we apply the same extraction protocol [Varga et al., 2001] to PM collected at a polluted urban site in Copenhagen, at a rural site in Melpitz and at the remote site Storm Peak Laboratory, where the latter is located at high altitude.

\section{Theory}

[7] Köhler theory describes the saturation ratio of water $(S)$ over an aqueous solution droplet by:

$$
S=a_{w} \exp \left(\frac{4 \sigma M_{w}}{R T \rho_{w} D}\right)
$$

where $a_{w}$ is the water activity, $\sigma$ is the surface tension, $M_{w}$ is the molar mass of water, $\rho_{w}$ is the density of water, $R=$ $8.314 \mathrm{~J} /(\mathrm{Kmol})$ is the universal gas constant, $T$ is the absolute temperature and $\mathrm{D}$ is the droplet diameter.

[8] Petters and Kreidenweis [2007] introduced the hygroscopicity parameter $\kappa$ and formulated the Köhler equation as:

$$
S=\frac{D^{3}-D_{p}^{3}}{D^{3}-D_{p}^{3}(1-\kappa)} \exp \left(\frac{4 \sigma M_{w}}{R T \rho_{w} D}\right)
$$

where $D_{p}$ is the dry particle diameter and $\kappa$ is a dimensionless hygroscopicity parameter ranging from about 0 for nonhygroscopic components to $\sim 1.4$ for very hygroscopic species. The $\kappa$ value of mixed particles can be estimated from the simple mixing rule:

$$
\kappa_{\text {add }}=\sum \varepsilon_{i} \kappa_{i}
$$

where $\varepsilon_{i}$ is the volume fraction of the species $\mathrm{i}$ in the dry particles [Petters and Kreidenweis, 2007].

\section{Methods}

\subsection{Sampling of Particulate Matter}

[9] An urban measurement station is located at the busy street $\mathrm{HC}$ Andersens Boulevard ( $\left.\mathrm{HCAB}, 55^{\circ} 40^{\prime} \mathrm{N}, 12^{\circ} 34^{\prime} \mathrm{E}\right)$ in central Copenhagen, Denmark ( 60,000 vehicles/day). Filter samples were collected on a daily basis using a $\mathrm{PM}_{10}$ Digitel DHA-80 High Volume Sampler. The sample flow rate was $720 \mathrm{~m}^{3} /$ day, and quartz filters (QR100; $150 \mathrm{~mm}$ diameter) were from Advantec (Frisenette, Denmark), and preheated at $450^{\circ} \mathrm{C}$ for 8 hours prior to use. Half of each of the daily filters from July 15-31, 2010 were pooled for subsequent extraction of HULIS. The filters were stored at $-18^{\circ} \mathrm{C}$ prior to analysis. For measurements of organic carbon (OC) and elemental carbon (EC) tandem filter samples were collected "quartz-behind-quartz," which enables correction for the positive sampling artifact. The tandem filters were sampled on a daily basis using a $\mathrm{PM}_{2.5}$ SEQ-47/50 Low Volume Sampler (Sven Leckel, Germany). The sample flow rate was $55 \mathrm{~m}^{3} /$ day, and quartz filters (QMA; $47 \mathrm{~mm}$ diameter) were from Whatmann (Frisenette, Denmark), and preheated at $450^{\circ} \mathrm{C}$ for 8 hours prior to use. The filters were stored at $-18^{\circ} \mathrm{C}$ prior to analysis of EC and OC. The HCAB measurement station and the monitoring are parts of and maintained by the Danish National Air Quality Monitoring Programme [Ellermann et al., 2011].

[10] A continental background station is located in the village of Melpitz, Germany (Mel, $\left.51^{\circ} 32^{\prime} \mathrm{N}, 12^{\circ} 54^{\prime} \mathrm{E}\right)$ and it is operated by the Leibniz Institute for Tropospheric Research (IfT), Leipzig. The measurement site is situated on a 100 year old meadow and is surrounded by agricultural areas. Daily filter samples were taken with a high volume sampler (DIGITEL DHA-80, Walter Riemer Messtechnik, Germany) with a $\mathrm{PM}_{2.5}$ inlet. The flow rate was $720 \mathrm{~m}^{3} /$ day. The quartz fiber filters (MK 360, Munktell, Sweden, $15 \mathrm{~cm}$ diameter) used were pre-heated for 24 hours at $105^{\circ} \mathrm{C}$ prior to usage to remove residual carbonaceous contamination. For the purpose of this study $22.45 \%\left(34.56 \mathrm{~cm}^{2}\right)$ of each filter from January 1 st to February 25th, 2009 were pooled. The filter samples were stored at room temperature for some time before HULIS extraction was carried out. A detailed description of the field station and the measurements is given by Spindler et al. [2010].

[11] Storm Peak Laboratory (SPL, $40^{\circ} 27^{\prime} \mathrm{N},-106^{\circ} 45^{\prime} \mathrm{W}$, $3210 \mathrm{~m}$ asl), operated by the Desert Research Institute (DRI), is located on the west summit of Mt. Werner in the Park Range near Steamboat Springs in northwestern Colorado, USA. This site has been used in cloud and aerosol studies for more than 25 years [e.g., Hallar et al., 2011; Lowenthal et al., 2002; Borys and Wetzel, 1997]. SPL is situated at treeline on a $70 \mathrm{~km}$ ridge oriented perpendicular 
to the prevailing westerly winds. SPL experiences transport from distant sources including urban areas, power plants, and wildfires [Obrist et al., 2008]. The filters used for collection of $\mathrm{PM}_{2.5}$ were $8^{\prime \prime} \times 10^{\prime \prime}$ Teflon-impregnated glass fiber filters (TIGF) (T60A20, Pall Corporation, USA). They were pre-cleaned by sonicating in dichloromethane for $10 \mathrm{~min}$ followed by $10 \mathrm{~min}$ in methanol, then dried overnight at a temperature of $30^{\circ} \mathrm{C} . \mathrm{PM}_{2.5}$ was sampled for 26 days from August 7th to September 2nd, 2010, with a flow rate of $\sim 1.2 \mathrm{~m}^{3} / \mathrm{min}$. The filter sample used in this study was kept frozen until the extraction took place.

\subsection{Extraction of HULIS}

[12] HULIS were extracted according to the protocol described by Varga et al. [2001] with modifications to upscale the extraction of relatively large amounts of HULIS. Portions of the aerosol filters were extracted with Milli-Q water with a reduction of total organic carbon (TOC) (18.2 MOhm, TOC $<4 \mathrm{ppb}$ ) in ultrasonic bath for $30 \mathrm{~min}$. The extracts were filtered through $0.45 \mu \mathrm{m}$ syringe filters. The $\mathrm{pH}$ of the filtered aqueous aerosol extracts was adjusted to 2 with concentrated $\mathrm{HCl}$ (Sigma-Aldrich) and passed through preconditioned Oasis HLB cartridges (Waters, Germany, sorbent mass $60 \mathrm{mg}$ ) with a flow rate of less than $\sim 1 \mathrm{ml} / \mathrm{min}$. The HULIS were eluted with $5-10 \mathrm{~mL}$ of methanol (Fluka, $>99.9 \%$ ) per cartridge. The methanol was evaporated from the sample in a rotary evaporator and the sample was diluted in pure water and kept frozen until further use. The concentrations of water soluble organic carbon (WSOC) and inorganic ions in the filtered aqueous aerosol extracts and in the HULIS extracts were measured as described below.

\subsection{Measurements of EC, OC, WSOC and Ions}

[13] The measurements of EC and OC were carried out differently for each of the field stations. The $\mathrm{PM}_{2.5}$ fractions collected at HCAB were routinely analyzed using a thermaloptical transmittance instrument from Sunset laboratories Inc. [Birch and Cary, 1996], according to the EUSAAR-2 protocol [Cavalli et al., 2010]. Punches of $1.5 \mathrm{~cm}^{2}$ were analyzed from the front and back filter, of which the latter can be subtracted from the front filter to correct for positive adsorptive artifacts during sampling. However, for comparison to the measurements in the other environments only the measurements based on the front filter are included in calculations. The instrument was internally calibrated by a methane standard, and the daily performance was quality controlled using blank filters and controls prepared from $40 \mu \mathrm{g}$ sucrose standards.

[14] For Mel the analysis of OC/EC was carried out with a total carbon analyzer (C-mat 5500, Ströhlein, Germany). Filter pieces were thermographically examined following a protocol without any optical correction (VDI 2465 Part 2, 1999, guideline for EC analysis in Germany). OC was evaporated at $650^{\circ} \mathrm{C}$ in pure nitrogen and catalytically converted to $\mathrm{CO}_{2}$, while $\mathrm{EC}$ was burnt at the same temperature in an oxygen atmosphere. $\mathrm{CO}_{2}$ was measured by a nondispersive infrared detector (NDIR). More details of the method are given by Spindler et al. [2010] and Neusüss et al. [2002].

[15] The measurements of OC/EC at SPL were carried out with a semi-continuous EC-OC field analyzer from Sunset Laboratory. The EPA/NIOSH TOT analysis method, also known as the Speciation Trends Network (STN) method protocol [Peterson and Richards, 2002] was applied. During July daily off-line measurements of OC/EC using the IMPROVE_A method [Chow et al., 2007] were carried out on quartz behind quartz filters sampled with a medium volume sampler. The off-line measurements of OC/EC during July were used for the calibration of the continuous measurements of OC/EC during the rest of the campaign, when the PM used in this study was sampled. An estimation of the positive sampling artifact during August is thus based on the off-line results from July. Since EC and OC are operationally defined and different approaches and protocols are used for the three sites, the reported concentrations cannot be directly compared.

[16] Analysis for WSOC and inorganic ions was performed at IfT in Leipzig on samples from all three field stations. The concentration of WSOC was measured in the filtered PM water extracts (WE) and in the HULIS samples using a TOC- $\mathrm{V}_{C P H}$ analyzer (Shimadzu, Japan) in the nonpurgable organic carbon (NPOC) mode [van Pinxteren et al., 2009].

[17] An ICS300 ion chromatography (IC) system (Dionex, USA) was used to measure the concentrations of inorganic ions in the WE and HULIS samples from all three locations. The anions chloride $\left(\mathrm{Cl}^{-}\right)$, sulfate $\left(\mathrm{SO}_{4}^{2-}\right)$, nitrate $\left(\mathrm{NO}_{3}^{-}\right)$and oxalate $\left(\mathrm{C}_{2} \mathrm{O}_{4}^{2-}\right)$ were separated on an AS18 column $(2 \times$ $250 \mathrm{~mm})$ using a potassium hydroxide eluent $(18-40 \mathrm{mM})$ at a flow rate of $0.28 \mathrm{ml} / \mathrm{min}$, while for the cations ammonium $\left(\mathrm{NH}_{4}^{+}\right)$, potassium $\left(\mathrm{K}^{+}\right)$, sodium $\left(\mathrm{Na}^{+}\right)$, calcium $\left(\mathrm{Ca}^{2+}\right)$, and magnesium $\left(\mathrm{Mg}^{2+}\right)$ a CS16 column $(3 \times 250 \mathrm{~mm})$ was used with a methanesulphonic acid eluent $(41 \mathrm{mM})$ at a flow rate of $0.40 \mathrm{ml} / \mathrm{min}$.

\subsection{Measurements of Hygroscopic Growth and CCN Activity}

[18] Aerosol particles were generated from water solutions using an atomizer with a bottle volume of $\sim 250 \mathrm{~mL}$. The particles were dried to $R H=4-20 \%$ using dry filtered air and a silica gel diffusion dryer. The aerosol flow was split in two, so that measurements of hygroscopic growth and $\mathrm{CCN}$ activity could be performed in parallel. The mobile version of the Leipzig Aerosol Cloud Interaction Simulator (LACIS) was used for measurements of hygroscopic growth [Jurányi et al., 2009]. Particles with a mobility diameter of $200 \mathrm{~nm}$ or $250 \mathrm{~nm}$ were selected with a differential mobility analyzer (DMA, type Vienna Medium). Aerosol and sheath air were humidified (aerosol: MH-110-12S-4, sheath air: PH-30T24KS, Perma Pure) to well defined dew point temperatures in the range $19.00^{\circ} \mathrm{C}$ to $19.99^{\circ} \mathrm{C}$ before entering the flow tube. The wall temperature of the flow tube was kept at $20.00^{\circ} \mathrm{C}$. The aerosol particles have $\sim 2.7 \mathrm{~s}$ residence time in the flow tube while exposed to the controlled RH. The obtained RH was calibrated by use of ammonium sulfate $(>99.999 \%$ Sigma-Aldrich) particles and the theoretical values for ammonium sulfate particles were calculated from equation (1) at $T=293.15 \mathrm{~K}$ with $\sigma=0.0728 \mathrm{Nm}^{-1}$, where the parameterization of $a_{w}$ was obtained from the Aerosol Inorganic Model (AIM) [Wexler and Clegg, 2002]. At the outlet of the flow tube an optical particle spectrometer using visible light detects the size of the grown particles. The spectrometer was calibrated using PSL particles of six different sizes ranging from $269 \mathrm{~nm}$ to $1020 \mathrm{~nm}$ in diameter. 
Table 2. Average Concentrations of Elemental Carbon (EC), Organic Carbon (OC), Water Soluble Organic Carbon (WSOC) and HULIS-C for the Three Sites in Units of $\mu \mathrm{gC} / \mathrm{m}^{3 \mathrm{a}}$

\begin{tabular}{lcccc}
\hline Sample & EC & OC & WSOC & HULIS-C \\
\hline HCAB & 1.96 & 2.82 & 2.82 & - \\
Mel & 2.24 & 3.30 & 2.36 & 1.16 \\
SPL & 0.05 & 0.74 & 0.46 & 0.24 \\
\hline
\end{tabular}

${ }^{\mathrm{a}}$ All results are for $\mathrm{PM}_{2.5}$ except for WSOC from $\mathrm{HCAB}$ which is for $\mathrm{PM}_{10}$. The concentration of HULIS-C could not be inferred for HCAB due to the presence of methanol in the HULIS water solution.

For dry ammonium sulfate particles and for dry WE particles a refractive index $(R I)$ of 1.53 was used. For Suwannee River Fulvic Acid Standard (SRFA) a $R I=1.63$ was used, and for the HULIS samples a range of realistic RI (1.561.68) were applied in the data analysis [Hoffer et al., 2006; Dinar et al., 2008]. The change in refractive indices for the hydrated particles was taken into account by using a volume mixing rule as described by Kiselev et al. [2005]. The volumes of the dried particles were derived from the mobility diameter assuming spherical particles, which is a good assumption for HULIS particles [Hoffer et al., 2006].

[19] With respect to the measurements of CCN activity a differential mobility analyzer (DMA, type Vienna Medium) was used to select particle sizes corresponding to a certain electrical mobility. The number concentration of $\mathrm{CCN}$ was measured using a $\mathrm{CCN}$ counter $(\mathrm{CCN}-\mathrm{C})$ from Droplet Measurement Technologies (DMT), operated in parallel with a TSI 3010 condensation particle counter (CPC) measuring the total number concentration of particles. Corresponding values of critical supersaturation $\left(S S_{c}\right)$ and critical mobility particle diameter $\left(D_{c}\right)$ were inferred from sigmoidal fits to $[\mathrm{CCN}] /[\mathrm{CN}]$ vs $D_{p}$, where doubly charged particles were taken into account. The $S S$ of the $C C N$ counter was calibrated using ammonium sulfate particles $(>99.999 \%$, SigmaAldrich). The theoretical values for ammonium sulfate particles were calculated from equation (1) at $298.15 \mathrm{~K}$ and with $\sigma=0.072 \mathrm{Nm}^{-1}$, where the parameterization of $a_{w}$ was obtained from the AIM [Wexler and Clegg, 2002].

\section{Results and Discussion}

\subsection{Chemical Characterization of the Sampled Particulate Matter}

[20] The concentrations of EC, OC, WSOC and carbon mass of HULIS (HULIS-C) from the three sites during the PM-sampling are included in Table 2. The concentrations of $\mathrm{EC}$ and $\mathrm{OC}$ at $\mathrm{HCAB}$ and Mel are of the same order of magnitude, and at SPL the concentrations are significantly lower which is particularly pronounced for EC. The high ratio of WSOC $\left(2.82 \mu \mathrm{gC} / \mathrm{m}^{3}\right)$ to $\mathrm{OC}\left(2.82 \mu \mathrm{gC} / \mathrm{m}^{3}\right)$ of $100 \%$ at $\mathrm{HCAB}$ is ascribed to the WSOC being extracted from $\mathrm{PM}_{10}$ whereas the $\mathrm{OC}$ is based on $\mathrm{PM}_{2.5}$. Lin et al. [2010b] found significant concentrations of WSOC in supermicron PM $(3.2 \mu \mathrm{m}<D<18 \mu \mathrm{m})$ on impactor samples, but only very small HULIS-C to WSOC ratios as opposed to the HULIS-C to WSOC ratio for PM with $D<$ $3.2 \mu \mathrm{m}$. A concentration of $\mathrm{OC}=2.15 \mu \mathrm{gC} / \mathrm{m}^{3}$ for the $\mathrm{PM}_{2.5}$ is obtained when correcting for the positive sampling artifact at HCAB. Salma et al. [2007] showed that concentrations corresponding to $17 \%$ and $28 \%$ respectively of the HULIS-C and WSOC collected on the front filter could be extracted from the back-up filter. In our study back-up filters were not applied when sampling PM for HULIS extraction, so concentrations of OC, WSOC and HULIS-C reported in Table 2 are not corrected for the positive sampling artifact. It was not possible to calculate the HULIS concentration at $\mathrm{HCAB}$ due to some $\mathrm{MeOH}$ still being present in the sample ( $2 \%$ concentration by mass in aqueous solution) after extraction.

[21] For Melpitz the ratio of the concentrations of WSOC $\left(2.36 \mu \mathrm{gC} / \mathrm{m}^{3}\right)$ to $\mathrm{OC}\left(3.30 \mu \mathrm{gC} / \mathrm{m}^{3}\right)$ is $72 \%$ and the ratio of HULIS-C $\left(1.16 \mu \mathrm{gC} / \mathrm{m}^{3}\right)$ to WSOC is $49 \%$. The highest concentrations of OC and $\mathrm{EC}\left(2.24 \mu \mathrm{gC} / \mathrm{m}^{3}\right)$ in this study are found at Melpitz. However, during the winter season when easterly winds dominate significantly higher concentrations of $\mathrm{OC}$ and EC can be observed, which can be attributed to anthropogenic emissions [Spindler et al., 2010]. For SPL the estimated concentration of OC in the $\mathrm{PM}_{2.5}$ was $0.74 \mu \mathrm{gC} / \mathrm{m}^{3}$, and the sampling artifact was estimated to account for $\sim 0.14 \mu \mathrm{gC} / \mathrm{m}^{3}$. The ratio of WSOC $\left(0.46 \mu \mathrm{gC} / \mathrm{m}^{3}\right)$ to OC was $64 \%$ and the ratio of HULIS-C $\left(0.24 \mu \mathrm{gC} / \mathrm{m}^{3}\right)$ to WSOC was $53 \%$. The ratios of HULIS-C to WSOC close to $50 \%$ are similar to those reported by Kiss et al. [2002] and Lin et al. [2010b] for similar extractions. The low concentration of EC $\left(0.05 \mu \mathrm{gC} / \mathrm{m}^{3}\right)$ at SPL is an upper estimate, since the concentration most of the time was below the detection limit. A low concentration of EC is typical for sites at high altitudes [Krivácsy et al., 2001].

[22] In the study by Lin et al. [2010b] an overview of the wide range of reported concentrations of HULIS is included. They used a conversion factor of 1.9 to convert from mass of carbon to mass of HULIS as reported by Kiss et al. [2002]. For comparison the HULIS-C concentrations in this study of 1.16 and $0.24 \mu \mathrm{gC} / \mathrm{m}^{3}$ would with the same conversion factor correspond to total HULIS concentrations of 2.20 and $0.46 \mu \mathrm{g} \mathrm{m}^{-3}$ respectively for Mel and SPL. A low HULIS concentration would be expected at SPL since Feczko et al. [2007] concluded that the HULIS concentration decreases exponentially with altitude. For Melpitz the concentration is lower than the reported winter concentration of $4.4 \mu \mathrm{g} \mathrm{m}^{-3}$ at the rural background site K-puszta [Kiss et al., 2002].

[23] The measured concentrations of ions in the WEs are included in Table 3. At HCAB the water soluble inorganic aerosol is on a molar basis dominated by $\mathrm{NH}_{4}^{+}$and $\mathrm{SO}_{4}^{2-}$ with moderate concentrations of $\mathrm{Na}^{+}, \mathrm{Ca}^{2+}, \mathrm{NO}_{3}^{-}$and $\mathrm{Cl}^{-}$. It seems reasonable that the aerosol at $\mathrm{HCAB}$ is dominated by local urban pollution. A slight influence from marine air masses due to the location close to the sea and the presence of $\mathrm{Na}^{+}$and $\mathrm{Cl}^{-}$seems reasonable and in accordance with a source apportionment study for the site carried out by Massling et al. [2011]. Elevated levels of $\mathrm{NH}_{4}^{+}$and $\mathrm{NO}_{3}^{-}$due to livestock have been observed in aerosol particles [Lammel et al., 2004], and it is likely that it to some extend could influence the aerosol at HCAB. At Melpitz the aerosol is dominated by $\mathrm{NH}_{4}^{+}$and $\mathrm{NO}_{3}^{-}$which indicates influence from agricultural activities [Lammel et al., 2004]. A significant concentration of $\mathrm{SO}_{4}^{2-}$ is also found, which is typical for the long range transported aerosol at Melpitz [Spindler et al., 2010]. At SPL $\mathrm{NH}_{4}^{+}$and $\mathrm{SO}_{4}^{2-}$ dominate with smaller amounts of $\mathrm{Na}^{+}$and $\mathrm{Ca}^{2+}$ present. The presence of $\mathrm{NH}_{4}^{+}$and $\mathrm{SO}_{4}^{2-}$ at SPL has also been reported from a study with an aerosol mass spectrometer (AMS) [Jimenez et al., 2009], and 
Table 3. Concentration of Measured Ions and WSOC in Water Extracts (WE) and Aqueous HULIS Samples ${ }^{\mathrm{a}}$

\begin{tabular}{|c|c|c|c|c|c|c|c|c|c|c|c|}
\hline Sample & $\mathrm{V} / \mathrm{mL}$ & $\mathrm{Cl}^{-}$ & $\mathrm{NO}_{3}^{-}$ & $\mathrm{SO}_{4}^{2-}$ & $\mathrm{C}_{2} \mathrm{O}_{4}^{2-}$ & $\mathrm{Na}^{+}$ & $\mathrm{NH}_{4}^{+}$ & $\mathrm{K}^{+}$ & $\mathrm{Mg}^{2+}$ & $\mathrm{Ca}^{2+}$ & WSOC \\
\hline HCAB-WE & 100 & 3.013 & 12.181 & 37.02 & 2.643 & 5.534 & 7.534 & 1.198 & 0.808 & 5.558 & 43.2 \\
\hline H HUL & 10 & 2.23 & 1.229 & 0.450 & 0.232 & 0.980 & 0.318 & 0.282 & 0.042 & 0.567 & - \\
\hline HUL/WE \% & - & 7.41 & 1.01 & 0.121 & 0.879 & 1.77 & 0.422 & 2.35 & 0.524 & 1.02 & - \\
\hline Mel-WE & 204 & 1.099 & 28.36 & 18.73 & 0.019 & 0.419 & 13.67 & 1.028 & 0.054 & 0.244 & 11.81 \\
\hline M HUL & 14 & 4.435 & 1.652 & 1.045 & 0.037 & 0.806 & 1.063 & 0.203 & 0.073 & 0.754 & 84.57 \\
\hline HUL/WE \% & - & 27.8 & 0.40 & 0.38 & 39.86 & 13.23 & 0.535 & 1.356 & 9.36 & 21.28 & 49.26 \\
\hline SPL-WE & 255 & 0.034 & 0.719 & 15.28 & 2.19 & 1.363 & 3.460 & 0.794 & 0.408 & 2.109 & 17.45 \\
\hline S HUL & 19 & 4.005 & 0.846 & 1.555 & 0.054 & 0.368 & 0.161 & 0.095 & 0.000 & 0.482 & 124.3 \\
\hline HUL/WE \% & - & 865 & 8.76 & 0.758 & 0.396 & 2.01 & 0.347 & 0.895 & 0.00 & 1.70 & 53.1 \\
\hline SRFA & 25 & 0.052 & 0.034 & 0.1965 & 0.559 & 0.022 & 0.286 & 0.235 & 0.176 & 0.748 & 286.6 \\
\hline
\end{tabular}

${ }^{\mathrm{a}}$ The ratio of the amount of ions and WSOC in the WE to the HULIS samples are included in \%. All WE were filtered with a syringe filter with a pore size of $0.45 \mu \mathrm{m}$ before measurements. The volumes of the solutions in $\mathrm{mL}$ are given in the second column, and all other measurements are in units of milligrams pr liter of solution $(\mathrm{mg} / \mathrm{L})$ and for WSOC the unit is $\mathrm{mgC} / \mathrm{L}$.

it is typical for aerosol transported over long range to remote environments. The chemical characterization of the aerosols supports, that the sources of PM at the three different field stations differ.

\subsection{CCN Activity and Hygroscopic Growth of HULIS}

[24] The measured CCN activities of the HULIS samples are presented in Figure 2. The CCN activities of the HULIS samples are almost identical. Single $\kappa_{C C N}$ values of 0.077 , 0.089 and 0.095 have been inferred for HCAB, Melpitz and SPL respectively from least squares fit. The depicted error bars on the $S S_{c}$ correspond to \pm 2 standard deviations derived from the ammonium sulfate calibration curve with each data point weighted equally as described by Miller and Miller [2010]. The errors on the $D_{c}$ correspond to \pm 2 standard deviations inferred from the sigmoid fit to the ratio of $C C N$ to $C N$ versus $D_{p}$, where doubly charged particles are accounted for. In most cases the error on $D_{c}$ is negligible compared to the error on $S S_{c}$. For the lower $S S$ the temperature measured inside the column of the $\mathrm{CCN}$ counter is very close to the $25^{\circ} \mathrm{C}$ which was assumed for the calibration of the $S S$. However, for the higher $S S$ it is likely that the temperatures at which the ammonium sulfate particles activate are up to $\sim 33^{\circ} \mathrm{C}$, so the reported $S S_{c}$ may be slightly overestimated in those cases.

[25] To test for a potential effect of the pore size in the syringe filters a part of the water extracts from SPL and Mel PM was filtered using a syringe filter with a pore size of $0.22 \mu \mathrm{m}$ (for the HCAB sample there was not enough PM available to do this). The same procedures and analysis were applied to these filtered aqueous extracts as described in section 3. As for the HCAB HULIS sample the measured WSOC was elevated in these final HULIS extracts, which is ascribed to $\mathrm{MeOH}$ still remaining in the samples. CCN activity was however reproduced with good agreement for both Mel and SPL. It is reasonable to conclude that the CCN activity is independent of the pore size $(0.45 \mu \mathrm{m}$ or $0.22 \mu \mathrm{m})$ used for the studied samples, and also that the small amount of $\mathrm{MeOH}$ remaining in the HCAB HULIS sample did not affect the measured $\mathrm{CCN}$ activity significantly. The $\mathrm{CCN}$ activities are similar to some previous results [Ziese et al., 2008; Fors et al., 2010], but significantly higher CCN activities have also been reported as depicted in Figure 1 [Dinar et al., 2006a; Asa-Awuku et al., 2008]. The measured CCN activity of SRFA is similar to the one reported by Dinar et al. [2006a] within the errors. The HULIS samples are exposed to very low pressures during isolation, so it is not expected that volatile compounds would end up in the HULIS samples in general. This is in line with the derived $\mathrm{CCN}$ activity $\left(\kappa_{C C N}\right)$ being independent of the temperature at activation inside the CCN counter within the errors.

[26] The hygroscopic growth of particles generated from the HULIS samples can be observed in Figure 3. For the data evaluation of the measurements with LACIS mobile the RI is needed. RIs of HULIS samples from Rondônia day: $1.653+0.0019 \mathrm{i}$ and night: $1.685+0.0016 \mathrm{i}$ were reported by Hoffer et al. [2006]. Dinar et al. [2008] reported RIs for HULIS originating from pollution: $1.595+0.049 \mathrm{i}$, smoke: $1.622+0.048 \mathrm{i}$ and K-puszta: $1.561+0.003 \mathrm{i}$. The reported errors are relatively small particularly in the latter study, and they cannot account for the differences between RI for different HULIS samples. Hence there is reason to believe that different HULIS samples have different RI. We evaluated the data from LACIS applying the range of RI $=1.56-1.68$ for all three HULIS samples. The vertical error bars for the atmospheric HULIS samples in Figure 3 cover the span given by the used RI interval and can therefore not be

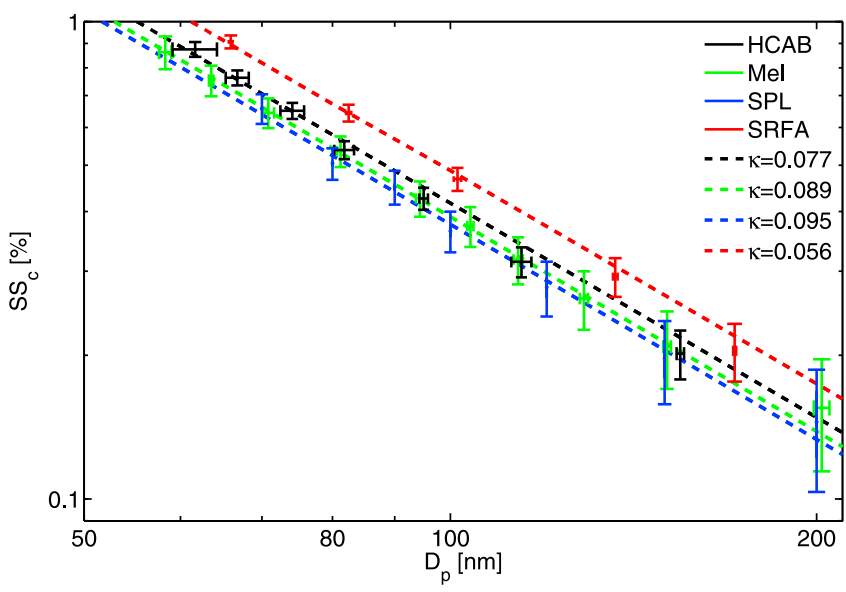

Figure 2. The measured CCN activities of the HULIS samples originating from SPL, Melpitz and HCAB and for SRFA. The error bars correspond to \pm 2 standard deviations. The dashed lines correspond to constant $\kappa$ values of 0.056 , $0.077,0.089$ and 0.095 for SRFA, HCAB, Mel and SPL respectively. Details about the chemical composition of the HULIS samples are presented in Table 3. 


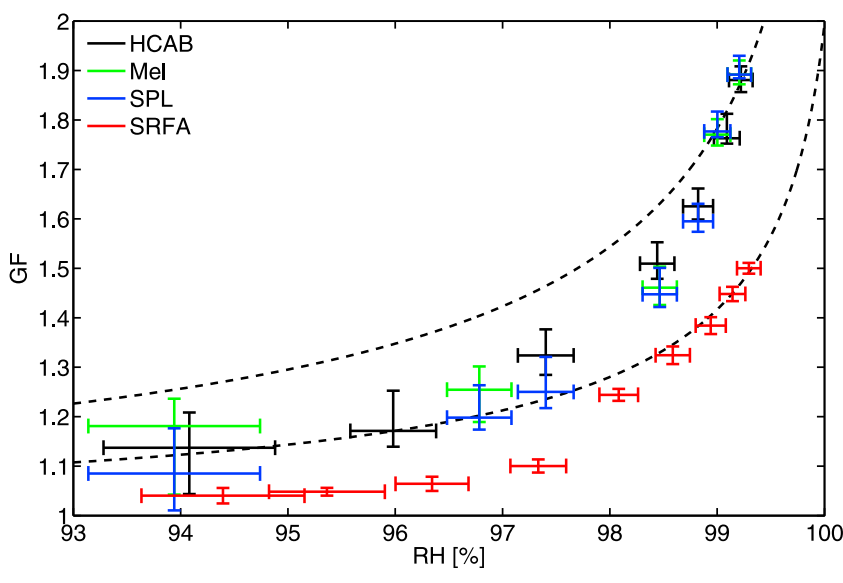

Figure 3. The growth factors for $250 \mathrm{~nm}$ HULIS and SRFA particles measured with mobile LACIS. A refractive index of 1.63 has been assumed for SRFA and the averages for the HULIS samples. The top and bottom of the error bars for the HULIS samples correspond to a RI $=1.56$ and 1.68 respectively. For SRFA the vertical error bars are the random errors corresponding to \pm 2 standard deviations from inferring the GF. The errors on the $R H$ correspond to \pm 2 standard deviations. The dashed lines correspond to constant $\kappa$ values of 0.03 and 0.07 respectively. For the chemical composition of the samples see Table 3 .

considered random errors. The random error on the growth factor $G F$ was calculated as the standard deviation of the mean of a gaussian distribution as described by Miller and Miller [2010]. Those random errors are included for the SRFA in Figure 3, but they are negligible compared to the uncertainty in choosing the right value of RI for the atmospheric HULIS samples. The RI of the wetted particles are calculated from volume weighted addition of RI assuming the imaginary part is negligible. When the particle growth is modest, it can be seen that the results are sensitive to the chosen RI of the dry particles. It is evident that the $\kappa$ values inferred from the $G F\left(\kappa_{G F}\right)$ increase with increasing $R H$. The errors on the $R H$ depicted in Figure 3 are inferred from several ammonium sulfate calibrations carried out before and in between the measurements. The $R H$ is significantly more well determined for high $R H$ due to the shape of the theoretical calibration curve of $G F$ vs $R H$ for ammonium sulfate. When measured data of hygroscopic growth do not follow lines of constant $\kappa$, as it is the case for our HULIS data depicted in Figure 3, possible reasons for that may be that the particle contains slightly soluble substances that only dissolve at higher $\mathrm{RHs}$ as discussed for mixed particles by Svenningsson et al. [2006]. Alternatively the non-ideality of the droplet solution changes with concentration, i.e. while it grows hygroscopically [Wex et al., 2009].

[27] For SRFA RI = 1.63 was used [Dinar et al., 2007]. Previous studies using a humidified tandem differential mobility analyzer (HTDMA) reported $G F_{90}=1.10$ [Brooks et al., 2004] and $G F_{90}=1.13$ [Dinar et al., 2007] for SRFA. Hence it is likely that the $G F \approx 1.05$ we observe for $R H=95 \%$ is too low, due to the imaginary part of the RI not being accounted for. Ziese et al. [2008] measured the hygroscopic growth of HULIS particles with LACIS and a High Humidity Tandem Differential Mobility Analyzer (HHTDMA) and found a good agreement between the two techniques for $G F \approx$ 1.7 , and model estimates suggested that the imaginary part was of minor importance for the investigated $G F \gtrsim 1$.7. It follows that the most reliable results of the hygroscopic growth are those for relatively high $G F$, where the $R I$ of the dry particles are of little importance due to the volume mixing rule of $R I$. Our focus will therefore be on the results for HULIS with $G F>$ 1.7 where the results are less influenced by the chosen RI. Hence the hygroscopic growth is similar for the three HULIS samples and a $\kappa_{G F}$ value close to 0.07 represents the most reliable data points well (see Figure 3). It is questionable whether the $G F=1.50$ obtained at a $R H=99.2 \%\left(\kappa_{G F}=0.03\right)$ for SRFA may be underestimated. However, a $\kappa$ value close to 0.03 may not be unreasonable considering that the $\kappa_{S R F A}=$ 0.044 and $\kappa_{S R F A}=0.056$ calculated for hygroscopic growth by Petters and Kreidenweis [2007] were based on the modest GF reported by Brooks et al. [2004] and Chan and Chan [2003] respectively.

[28] When considering the $\mathrm{CCN}$ activity and hygroscopic growth of the HULIS samples it is relevant to investigate to what degree inorganics may affect those properties. The most predominant measured inorganic ions such as $\mathrm{NO}_{3}^{-}$, $\mathrm{SO}_{4}^{2-}$ and $\mathrm{NH}_{4}^{+}$are removed quite efficiently (99.5\%) during the HULIS extraction as can be observed from Table 3 . However, some inorganic ions are present in the HULIS samples and by mass they constitute up to $6 \%$ of the HULIS samples (see Table 4). Among the inorganic ions the $\mathrm{Cl}^{-}$ concentration is the highest by mass (see Table 3 ) in all three atmospheric HULIS samples, most likely due to the addition of $\mathrm{HCl}$ during the extraction. Assuming that the simple $\kappa$ addition rule in equation (3) applies for the HULIS samples, the $\kappa$ values inferred from measurements were corrected by subtracting the contributions from the inorganic species. The resulting values are given in Table 4 as $\kappa_{G F}{ }^{*}$ and $\kappa_{C C N}{ }^{*}$. When converting the concentrations of inorganic ions reported in Table 3 to $\mathrm{mol} / \mathrm{L}$ the relevant salts can be considered. For the HCAB sample the charges add up to $\sim 0$, but for Mel and SPL the negative charges dominate, which is expected to be due to the concentration of $\mathrm{H}^{+}$not accounted for. The cations and anions can be combined into salts. The most abundant ions were taken into account first followed by assigning the remaining anions to the associated acids. Two parameters are used to obtain the volume of HULIS: the density of HULIS and the organic matter (OM), converted from the measured HULIS-C. The average ratio of OM to OC for the total of 23 HULIS samples investigated by Kiss et al. [2002] and Song et al. [2012] is 1.96 with a standard deviation of 0.08 . The average density of the 5 HULIS samples investigated by Dinar et al. [2006b] and Hoffer et al. [2006] is $1.57 \mathrm{~g} / \mathrm{cm}^{3}$, with a standard deviation of $0.09 \mathrm{~g} / \mathrm{cm}^{3}$. For the HCAB sample a HULIS yield of $50 \%$ is assumed, which is similar to the HULIS yield for the other two samples and a typical average of reported yields in the literature [Kiss et al., 2002]. Thus volume fractions of inorganic salts of $1 \%, 5 \%$ and $3 \%$ for $\mathrm{HCAB}$, Mel and SPL respectively are obtained (see Table 5). For the inorganic species the used $\kappa$ values are as reported by Petters and Kreidenweis [2007], Shantz et al. [2008], and Sullivan et al. [2009] and they are included in Table 4. For $\mathrm{HCl}$ and $\mathrm{HNO}_{3} \kappa$ values of 1.1 and 0.8 respectively were estimated based on Köhler curves calculated from parameterizations of $a_{w}$ obtained from the AIM [Wexler and Clegg, 2002]. 
Table 4. Mass of Ions Relative to Total Mass of Water Soluble Matter, Experimental $\kappa$ Values and $\kappa$ Values Estimated From Equation (3) ${ }^{\mathrm{a}}$

\begin{tabular}{|c|c|c|c|c|c|c|}
\hline \multirow[b]{2}{*}{ Sample } & \multirow[b]{2}{*}{$\frac{m_{\text {ion }}}{m_{\text {total }}}$} & \multicolumn{2}{|c|}{ Experimental } & \multicolumn{2}{|c|}{ Corrected for Inorganics } & \multirow{2}{*}{$\begin{array}{c}\kappa \text {-Addition } \\
\kappa_{\text {add,CCN }} \\
\end{array}$} \\
\hline & & $\kappa_{G F}$ & $\kappa_{C C N}$ & $\kappa_{G F} *$ & $\kappa_{C C N} *$ & \\
\hline HCAB-WE & 0.47 & 0.25 & 0.23 & & & $0.33 \pm 0.05$ \\
\hline HCAB HULIS & 0.015 & 0.07 & 0.077 & 0.06 & 0.07 & \\
\hline Mel-WE & 0.74 & 0.41 & 0.29 & & & $0.49 \pm 0.05$ \\
\hline Mel HULIS & 0.059 & 0.07 & 0.089 & 0.04 & 0.07 & \\
\hline SPL-WE & 0.42 & 0.22 & 0.22 & & & $0.30 \pm 0.06$ \\
\hline SPL HULIS & 0.031 & 0.07 & 0.095 & 0.03 & 0.056 & \\
\hline SRFA & 0.0042 & 0.03 & 0.056 & - & - & \\
\hline
\end{tabular}

${ }^{\text {a }}$ The estimate of the inorganic fraction of the HCAB HULIS sample is based on an estimate of a HULIS yield of $50 \%$. It is assumed that $m_{\text {total }}=1.9$. $m_{\text {HULIS-C }}+m_{\text {ion }}$ or $m_{\text {total }}=1.9 \cdot m_{W S O C}+m_{\text {ion }}$. Experimentally determined $\kappa$ values are also shown, together with the values corrected for the influence of inorganic material contained in the samples $\left(\kappa^{*}\right)$. The $\kappa_{\text {add }}$ values inferred from the $\kappa$-addition rule are included. For the WE the $\kappa_{a d d, C C N}$ values were calculated by use of equation (3) and by assuming $\rho_{W S O M}=1.4 \pm 0.2 \mathrm{~g} / \mathrm{cm}^{3}$, WSOM/WSOC $=1.9 \pm 0.3$, and $\kappa=0.07$ for water soluble organic compounds.

[29] When correcting the measured $\kappa_{C C N}$ for the influence of the total amount of inorganics, $\kappa_{C C N}{ }^{*}$ values for HULIS of $0.07,0.05$ and 0.07 are obtained for HCAB, Mel and SPL respectively. The absolute error on the $\kappa_{C C N}{ }^{*}$ values calculated from the standard deviations of the density and the $\mathrm{OM}$ to $\mathrm{OC}$ ratio is $<0.005$ for all 3 samples. It is uncertain how the ions would combine in the solid particle phase - but the sensitivity of $\kappa_{C C N}{ }^{*}$ to how the cations and anions were combined to form different salts in the calculations was negligible. The estimates of $\kappa_{C C N}{ }^{*}$ presented above may be considered lower bounds for the Mel and SPL samples, since it is likely that volatile species such as $\mathrm{HCl}$ and $\mathrm{NH}_{4} \mathrm{NO}_{3}$ will evaporate from the solution or from the aerosol particles during the particle generation or the drying process before the size selection. For the HCAB sample the estimated $\kappa$ value would be 0.06 if a HULIS yield of $30 \%$ was assumed instead of $50 \%$. If evaporation of volatile species from the particles occur after the size selection then the inferred $\kappa^{*}$ values for HULIS would be underestimated and the measured CCN activity would be expected to decrease with increasing $S S$ and temperature inside the $\mathrm{CCN}-\mathrm{C}$. Such a trend is not observed in Figure 2 for the Mel and SPL samples, but there seems to be a weak trend of decreasing $\mathrm{CCN}$ activity for increasing $S S$ for the HCAB sample. The latter sample was the only one that was exposed for less than 1 hour to the reduced pressures in the rotary evaporator during the isolation of HULIS, and the presence of $\mathrm{MeOH}$ in that HULIS sample indicates that volatile species thus could be present in the sample. The inferred $\kappa_{C C N}$ for the HCAB sample is 0.09 if only data with $S S<0.5 \%$ are considered. Taking all the above considerations into account the most reasonable estimates of the $\kappa_{C C N}{ }^{*}$ for HULIS only would be 0.07, 0.07 and 0.08 respectively for $\mathrm{HCAB}, \mathrm{Mel}$ and SPL, where errors of roughly $0.01-0.02$ in absolute values seem reasonable. A similar approach can be used for estimation of the $\kappa_{G F}{ }^{*}$ for pure HULIS and reasonable estimates of 0.06 , 0.04 and 0.05 for HCAB, Mel and SPL respectively can be obtained again with an estimated absolute error of 0.010.02 . When it comes to SRFA it is not necessary to correct for the inorganic contamination since it is very small $(<0.5 \%$ by mass). It is remarkable how similar the hygroscopic growth and $\mathrm{CCN}$ activity seems to be, when comparing pure atmospheric HULIS and SRFA.

[30] Our results suggest that HULIS samples that are expected to differ in organic composition have similar properties when it comes to hygroscopic growth and $\mathrm{CCN}$ activity. This finding could be supported by the results of low hygroscopicity of HULIS reported by Fors et al. [2010]. It is not easy to tell to what degree it could be the case in general, that most HULIS samples have relatively low $\kappa$ values. AsaAwuku et al. [2008] report very low concentration of inorganics in their HULIS sample with a relatively high CCN activity $\left(\kappa_{C C N}=0.33\right)$, so differences in the organic composition are expected to be of importance. Our results indicate that it may be important to correct for the inorganic contamination of HULIS samples, and we suggest that the fractional contribution to the total concentration from inorganic species always should be reported in similar studies. Our results also support that SRFA can be used as a model compound for the hygroscopic properties of atmospheric HULIS.

\subsection{CCN Activity and Hygroscopic Growth of Water Extracts of PM}

[31] The CCN activity of particles generated from the WEs are depicted in Figure 4 together with the theoretical

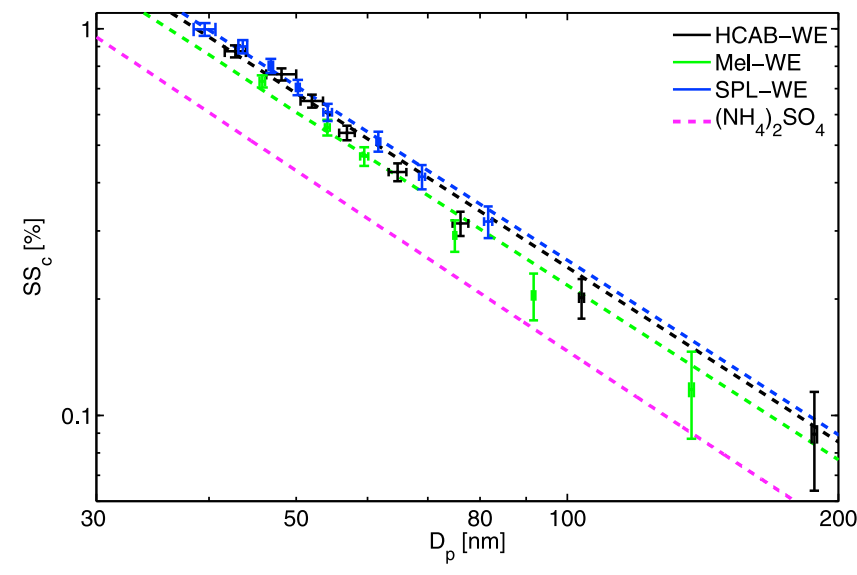

Figure 4. The CCN activity of particles generated from filtered water extracts of PM from SPL, Mel and HCAB. The dashed lines represent constant $\kappa$ values of $0.23,0.29$ and 0.22 respectively for HCAB (black), Mel (green) and SPL (blue) obtained by least squares fit to the data. The error bars correspond to \pm 2 standard deviations inferred from the calibration of the $S S$ and from the sigmoid fit respectively. The theoretical curve for ammonium sulfate (dashed magenta line) is included for comparison. For the chemical composition of the water extracts see Table 3. 


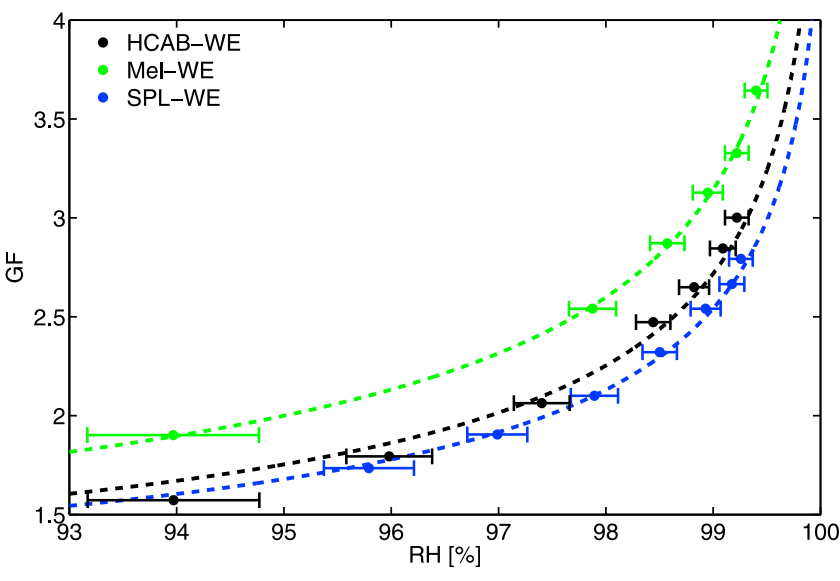

Figure 5. The measured growth factors for the filtered water extracts. For HCAB $D_{p}=250 \mathrm{~nm}$ and for Melpitz and SPL the results are for $D_{p}=200 \mathrm{~nm}$. A refractive index of 1.53 has been assumed for the dry particles in all cases. $\kappa$ values of $0.25,0.41$ and 0.22 respectively were obtained from least squares fit to the data from HCAB, Melpitz and SPL and are depicted as dashed lines. For the chemical composition of the water extracts see Table 3 .

value for pure ammonium sulfate for comparison. From least squares fit to the data $\kappa_{C C N}$ values of $0.23,0.29$ and 0.22 are obtained for the water extracts from HCAB (HCAB-WE), Melpitz (Mel-WE) and SPL (SPL-WE) respectively. The hygroscopic growth factors are depicted in Figure 5. The $\kappa_{G F}$ values are in this case $0.25,0.41$ and 0.22 respectively for HCAB-WE, Mel-WE and SPL-WE when only including data points with $G F>1.7$. A single $\kappa_{G F}$ value represents the results for Mel-WE and SPL-WE very well, but that is not the case for HCAB-WE, where a $\kappa_{G F}$ of 0.20 is obtained for the lowest $G F$. It is assumed that the results for the high $R H$ are more reliable considering random as well as systematic errors in line with the discussion of the $G F$ for the HULIS samples above. The mobility diameters of the dry particles were $D_{p}=200 \mathrm{~nm}$ except for HCAB-WE where $D_{p}=250 \mathrm{~nm}$ was used. With respect to the activation measurements the $\kappa_{C C N}$ values tend to decrease with increasing $S S$ data point by data point, which is mostly pronounced for Mel-WE and HCAB-WE. Since the $\kappa_{G F}$ s are relatively constant with respect to $R H s$ it is unlikely that changes in non-ideality or influence from slightly soluble substances is of significance for the water extracts. It is thus very likely that the trend can be explained by volatility of some of the species in the particles. With increasing $S S$ and thus increasing $T$ inside the $\mathrm{CCN}-\mathrm{C}$, the particles will tend to turn smaller and thus exhibit a smaller CCN activity than expected, which can explain the observed trend.

[32] An estimation of $\kappa_{\text {add }}$ for the WEs can be obtained from equation (3). The density of water soluble organic compounds and the ratio of water soluble organic matter (WSOM) to WSOC are needed to obtain the volume of the WSOM from the measured concentration of WSOC. A ratio of WSOM to WSOC of $1.9 \pm 0.4$ is assumed based on the results from an urban, a rural/continental and a remote environment as reported by Timonen et al. [2012], Kiss et al. [2002], and $Y u$ et al. [2005], respectively. The density of WSOM is assumed to be $1.4 \pm 0.2 \mathrm{~g} / \mathrm{cm}^{3}$ partly based on the densities reported by Turpin and Lim [2001] and partly based on the fact that about $50 \%$ of the WSOM is HULIS with a density of $\sim 1.57 \mathrm{~g} / \mathrm{cm}^{3}$. A $\kappa_{W S O M}=0.07$ was assumed as for HULIS. The concentrations of inorganic ions included in Table 3 were converted to moles, and cations and anions were paired starting out with the most abundant first. For HCAB-WE and Mel-WE there is a slight excess of negative charges, which is assumed to be due to the presence of $\mathrm{H}^{+}$not accounted for, so remaining anions are considered to represent acids, that are included in the $\kappa$-addition calculations. For SPL-WE there is a slight excess of positive charges, which could be due to anions that are not measured or cations binding to organics. Furthermore, the difference could in part be due to random errors. A small fraction of the cations are thus not accounted for in the $\kappa$-addition.

[33] As can be seen in Table 4 the estimated $\kappa_{\text {add }}$ values are $0.33 \pm 0.05,0.49 \pm 0.05$ and $0.30 \pm 0.06$ for HCABWE, Mel-WE and SPL-WE respectively, where the errors originate from the assumed ranges of the ratio of WSOM to WSOC and the density of WSOM. The estimated $\kappa_{\text {add }}$ values are thus systematically higher than the experimental $\kappa$ values for both sub- and supersaturated conditions, even when the uncertainty in WSOM properties is considered. An assumed slightly higher ratio of WSOM to WSOC could perhaps be justified from results reported in the literature [Turpin and Lim, 2001]. However, if the non-HULIS WSOM is highly oxidized, as would be expected with a high WSOM to WSOC ratio, then a $\kappa_{W S O M}$ higher than 0.07 should be expected, which would result in the $\kappa_{\text {add }}$ still being overestimated relative to measurements. In general some of the non-HULIS WSOM is comprised of sugars and short chained acids [Lin et al., 2010b], which typically have $\kappa$ values significantly higher than 0.07 [Petters et al., 2009]. Hence it seems like there is a tendency for the $\kappa$-addition method to overpredict the hygroscopicity of the studied particles generated from the WE. It is not possible to tell from these experiments if the overprediction is due to the composition of the generated particles being different to the bulk composition of the solution in the atomizer.

[34] In the current study the difference between $\kappa_{C C N}$ and $\kappa_{\text {add }}$ is particularly pronounced for Mel-WE, and it is likely that it to some degree can be ascribed to volatility of the generated aerosol particles. As can be seen from Table 3 the Mel-WE is dominated by $\mathrm{NH}_{4} \mathrm{NO}_{3}$, which has proven to

Table 5. The Densities, and $\kappa$ Values, and Volume Fractions Used for Calculations

\begin{tabular}{lccccc}
\hline \multicolumn{1}{c}{ Species } & $\rho\left(\mathrm{g} / \mathrm{cm}^{3}\right)$ & $\kappa$ & $\varepsilon(\mathrm{HCAB})(\%)$ & $\varepsilon(\mathrm{Mel})(\%)$ & $\varepsilon(\mathrm{SPL})(\%)$ \\
\hline $\mathrm{NaCl}$ & 2.17 & $1.28^{\mathrm{a}}$ & 0.42 & 0.85 & 0.27 \\
$\left(\mathrm{NH}_{4}\right)_{2} \mathrm{SO}_{4}$ & 1.77 & $0.61^{\mathrm{a}}$ & 0.13 & 0.73 & 0.21 \\
$\mathrm{NH}_{4} \mathrm{NO}_{3}$ & 1.73 & $0.67^{\mathrm{a}}$ & 0.14 & 1.11 & 0 \\
$\mathrm{NH}_{4} \mathrm{Cl}$ & 1.53 & $1.02^{\mathrm{b}}$ & 0 & 0.33 & 0 \\
$\mathrm{CaCl}_{2}$ & 2.15 & $0.48^{\mathrm{b}}$ & 0.19 & 0.87 & 0.39 \\
$\mathrm{Ca}\left(\mathrm{NO}_{3}\right)_{2}$ & 2.5 & $0.51^{\mathrm{b}}$ & 0.03 & 0 & 0 \\
$\mathrm{KNO}_{3}$ & 2.11 & $0.88^{\mathrm{b}}$ & 0.13 & 0 & 0.07 \\
$\mathrm{HCl}$ & 1.2 & $1.1^{\mathrm{c}}$ & 0 & 1.00 & 1.38 \\
$\mathrm{HNO}$ & 1.51 & $0.8^{\mathrm{c}}$ & 0 & 0 & 0.29 \\
$\mathrm{H}_{2} \mathrm{SO}_{4}$ & 1.84 & $0.7^{\mathrm{d}}$ & 0 & 0 & 0.39 \\
$\mathrm{HULIS}$ & 1.57 & - & 98.96 & 95.10 & 96.99 \\
\hline
\end{tabular}

${ }^{\mathrm{a}}$ Petters and Kreidenweis [2007].

${ }^{\mathrm{b}}$ Sullivan et al. [2009].

${ }^{\mathrm{c}}$ From Köhler curves based on $a_{w}$ inferred from the AIM

${ }^{\mathrm{d}}$ Shantz et al. [2008]. 
evaporate from mixed particles on short timescales at room temperature [Hightower and Richardson, 1988]. If evaporation of volatile species takes place before size selection of the particles, the measurements would change depending on the hygroscopicity of the volatile species compared to the hygroscopicity of the bulk. If evaporation takes place after the size selection of the particles then a reduction in particle size will dominate and lead to an underprediction of the hygroscopicity. The latter effect will be more significant for the CCN measurements and can explain the trend observed particularly for the HCAB-WE and Mel-WE as discussed above. For the SPL-WE the inorganic ions are dominated by $\mathrm{NH}_{4}^{+}$and $\mathrm{SO}_{4}^{2+}$, so volatility of the inorganic compounds would not be expected to be a significant problem, and the effect seems to be limited to the results from the CCN-C.

[35] Our results clearly indicate that it is important to take organic compounds into account when predicting the hygroscopic growth and CCN activity of ambient internally mixed organic/inorganic aerosol particles, since the inorganics alone would have a $\kappa$ value higher than $\sim 0.61$ as for pure $\left(\mathrm{NH}_{4}\right)_{2} \mathrm{SO}_{4}$ (see Table 3 ). The mass of water soluble species in ambient PM is typically dominated by inorganic species in particles with diameters larger than $200 \mathrm{~nm}$. Smaller particles that are more important for ambient CCN concentrations consist of a larger fraction of organic species [Andreae and Rosenfeld, 2008]. Thus the CCN activity of water extracts of PM will tend to overestimate the number concentration of ambient CCN [Medina et al., 2007]. Hence in the present study the average $\kappa$ values of the ambient $\mathrm{CCN}$ at the three sites are likely to be lower than reported here for the particles generated from the WE of sampled $\mathrm{PM}_{2.5}$ or $\mathrm{PM}_{10}$.

\section{Conclusion}

[36] The hygroscopic growth and $\mathrm{CCN}$ activity of particles generated from the water extracts and HULIS extracted from PM collected at a polluted urban site in Copenhagen, the rural site Melpitz and the remote site Storm Peak Laboratory were investigated. For the water extracts the inferred $\kappa_{G F}$ values were $0.25,0.41$ and 0.22 , and the inferred $\kappa_{C C N}$ values were $0.23,0.29$ and 0.22 respectively for the urban, rural and remote environment. It is very likely that the inferred $\kappa$ values are underestimated at the rural and urban site due to significant concentrations of volatile $\mathrm{NH}_{4} \mathrm{NO}_{3}$, particularly when it comes to $\kappa_{C C N}$. Measurements of inorganic ions, EC, OC and WSOC within the PM confirmed that the sources of aerosol particles most likely differed for the samples from the urban site (HCAB), the rural site (Mel) and the remote site (SPL). Concentrations of HULIS-C were 1.16 and $0.24 \mu \mathrm{gC} / \mathrm{m}^{3}$ at Mel and SPL respectively, and it was not inferred at HCAB. The measured hygroscopic growth and $\mathrm{CCN}$ activity were almost identical for the three HULIS samples and could be well represented by $\kappa_{G F}=$ 0.07 and $\kappa_{C C N}=0.08-0.10$ respectively. Small amounts of inorganic ions were present in the HULIS samples so the actual $\kappa$ values $\left(\kappa^{*}\right)$ for pure HULIS are estimated to be $\kappa_{G F}{ }^{*}=0.04-0.06 \kappa_{C C N}{ }^{*}=0.07-0.08$ with an estimated error of roughly 0.01 in absolute value. We suggest that the fraction of inorganic species in the HULIS samples always should be reported. The inferred $\kappa$ values for HULIS are thus smaller than reported in most earlier studies with the exception of the results by Fors et al. [2010].

[37] Acknowledgments. This work was supported by EUROCHAMP 2, EU FP7. We thank Gerald Spindler for providing filter samples from Melpitz. We thank Thomas Gnauk for EC/OC data from Melpitz and Konrad Müller for ion chromatography measurements. We thank Michael Schäfer and Paul Herenz for assistance in the laboratory at IfT. We thank A. Nenes for providing CCN data from the study by Asa-Awuku et al. [2008]. We thank Ian McCubbin and Ty Atkins for help with operations, and instrument installation at SPL. The Steamboat Ski Resort Corporation provided logistical support and in-kind donations. The DRI's SPL is an equal opportunity service provider and employer and is a permittee of the Medicine-Bow Routt National Forests. This material is based in part upon work supported by the National Science Foundation under grant AGS-0931431. Any opinions, findings, and conclusions or recommendations expressed in this material are those of the author(s) and do not necessarily reflect the views of the National Science Foundation.

\section{References}

Altieri, K. E., S. P. Seitzinger, A. G. Carlton, B. J. Turpin, G. C. Klein, and A. G. Marshall (2008), Oligomers formed through in-cloud methylglyoxal reactions: Chemical composition, properties, and mechanisms investigated by ultra-high resolution FT-ICR mass spectrometry, Atmos. Environ., 42, 1476-1490, doi:10.1016/j.atmosenv.2007.11.015.

Andreae, M. O., and D. Rosenfeld (2008), Aerosol-cloud-precipitation interactions. Part 1. The nature and sources of cloud-active aerosols, Earth Sci. Rev., 89, 13-41, doi:10.1016/j.earscirev.2008.03.001.

Asa-Awuku, A., A. P. Sullivan, C. J. Hennigan, R. J. Weber, and A. Nenes (2008), Investigation of molar volume and surfactant characteristics of water-soluble organic compounds in biomass burning aerosol, Atmos. Chem. Phys., 8, 799-812, doi:10.5194/acp-8-799-2008.

Baduel, C., D. Voisin, and J. L. Jaffrezo (2009), Comparison of analytical methods for Humic Like Substances (HULIS) measurements in atmospheric particles, Atmos. Chem. Phys., 9, 5949-5962, doi:10.5194/acp9-5949-2009.

Birch, M. E., and R. A. Cary (1996), Elemental carbon-based method for monitoring occupational exposures to particulate diesel exhaust, Aerosol Sci. Technol., 25(3), 221-241, doi:10.1080/02786829608965393.

Borys, R. D., and M. A. Wetzel (1997), Storm Peak Laboratory: A research, teaching and service facility for the atmospheric sciences, Bull. Amer. Meteor. Soc., 78, 2115-2123, doi:10.1175/1520-0477(1997)078<2115: SPLART $>2.0 . \mathrm{CO} ; 2$

Brooks, S. D., P. J. DeMott, and S. M. Kreidenweis (2004), Water uptake by particles containing humic materials and mixtures of humic materials with ammonium sulfate, Atmos. Environ., 38, 1859-1868, doi:10.1016/ j.atmosenv.2004.01.009

Calace, N., B. M. Petronio, R. Cini, A. M. Stortini, B. Pampaloni, and R. Udis (2001), Humic marine matter and insoluble materials in Antarctic snow, Intern. J. Environ. Anal. Chem., 79(4), 331-348, doi:10.1080/ 03067310108044393

Cavalli, F., et al. (2004), Advances in characterisation of size-resolved organic matter in marine aerosol over the North Atlantic, J. Geophys. Res., 109, D24215, doi:10.1029/2004JD005137.

Cavalli, F., M. Viana, K. E. Yttri, J. Genberg, and J.-P. Putaud (2010), Toward a standardised thermal-optical protocol for measuring atmospheric organic and elemental carbon: the EUSAAR protocol, Atmos. Meas. Tech., 3, 79-89, doi:10.5194/amt-3-79-2010.

Chan, M. N., and C. K. Chan (2003), Hygroscopic properties of two model humic-like substances and their mixtures with inorganics of atmospheric importance, Environ. Sci. Technol., 37, 5109-5115, doi:10.1021/ es034272o.

Chow, J. C., J. G. Watson, L.-W. Antony Chen, M. C. O. Chang, N. F. Robinson, D. Trimble, and S. Kohl (2007), The IMPROVE A temperature protocol for thermal/optical carbon analysis: Maintaining consistency with a long-term database, J. Air Waste Manage. Assoc., 57, 1014-1023, doi:10.3155/1047-3289.57.9.1014.

Cini, R., N. Degliinnocenti, G. Loglio, C. Oppo, G. Orlandi, A. M. Stortini, U. Tesei, and R. Udisti (1996), Air-sea exchange: Sea salt and organic microcomponents in Antarctic snow, Int. J. Environ. Anal. Chem., 63, $15-27$.

Decesari, S., M. C. Facchini, E. Matta, M. Mircea, S. Fuzzi, A. R. Chughtai, and D. M. Smith (2002), Water soluble organic compounds formed by oxidation of soot, Atmos. Environ., 36, 1827-1832, doi:10.1016/S13522310(02)00141-3.

Dinar, E., I. Taraniuk, E. R. Graber, S. Katsman, T. Moise, T. Anttila, T. F. Mentel, and Y. Rudich (2006a), Cloud condensation nuclei properties of 
model and atmospheric HULIS, Atmos. Chem. Phys., 6, 2465-2482, doi:10.5194/acp-6-2465-2006.

Dinar, E., T. F. Mentel, and Y. Rudich (2006b), The density of humic acids and humic like substances (HULIS) from fresh and aged wood burning and pollution aerosol particles, Atmos. Chem. Phys., 6, 5213-5224, doi:10.5194/acp-6-5213-2006.

Dinar, E., I. Taraniuk, E. R. Graber, T. Anttila, T. F. Mentel, and Y. Rudich (2007), Hygroscopic growth of atmospheric and model humic-like substances, J. Geophys. Res., 112, D05211, doi:10.1029/2006JD007442.

Dinar, E., A. Abo Riziq, C. Spindler, C. Erlick, G. Kiss, and Y. Rudich (2008), The complex refractive index of atmospheric and model humiclike substances (HULIS) retrieved by a cavity ring down aerosol spectrometer (CRD-AS), Faraday Discuss., 137, 279-295, doi:10.1039/b703111d.

Ellermann, T., C. Nordstrøm, J. Brandt, J. Christensen, M. Ketzel, and S. S. Jensen (2011), The Danish Air Quality Monitoring Programme: Annual summary for 2010, Tech. Rep. 836, 55 pp., Natl. Environ. Res. Inst., Aarhus Univ., Aarhus, Denmark.

Feczko, T., H. Puxbaum, A. Kasper-Giebl, M. Handler, A. Limbeck, A. Gelencsér, C. Pio, S. Preunkert, and M. Legrand (2007), Determination of water and alkaline extractable atmospheric humic-like substances with the TU Vienna HULIS analyzer in samples from six background sites in Europe, J. Geophys. Res., 112, D23S10, doi:10.1029/2006JD008331.

Feng, J., and D. Möller (2004), Characterization of water-soluble macromolecular substances in cloud water, J. Atmos. Chem., 48, 217-233.

Fors, E. O., et al. (2010), Hygroscopic properties of Amazonian biomass burning and European background HULIS and investigation of their effects on surface tension with two models linking H-TDMA to CCN-C data, Atmos. Chem. Phys., 10, 5625-5639, doi:10.5194/acp-10-5625-2010.

Gelencsér, A., A. Hoffer, Z. Krivácsy, G. Kiss, A. Molnar, and E. Mészáros (2002), On the possible origin of humic matter in fine continental aerosol, J. Geophys. Res., 107(D12), 4137, doi:10.1029/2001JD001299.

Gysel, M., E. Weingartner, S. Nycki, D. Paulsen, U. Baltensberger, I. Galambos, and G. Kiss (2004), Hygroscopic properties of water-soluble matter and humic-like organics in atmospheric fine aerosol, Atmos. Chem. Phys., 4, 35-50, doi:10.5194/acp-4-35-2004.

Hallar, A. G., D. H. Lowenthal, G. Chirokova, C. Wiedinmyer, and R. D. Borys (2011), Persistent daily new particle formation at a mountain-top location, Atmos. Environ., 45, 4111-4115, doi:10.1016/j.atmosenv.2011. 04.044

Havers, N., P. Burba, J. Lambert, and D. Klockow (1998), Spectroscopic characterization of humic-like substances in airborne particulate matter, J. Atmos. Chem., 29, 45-54.

Hightower, R. L., and C. B. Richardson (1998), Evaporation of ammonium nitrate particles containing ammonium sulfate, Atmos. Environ., 22, 2587-2591.

Hoffer, A., G. Kiss, M. Blazsó, and A. Gelencser (2004), Chemical characterization of humic-like substances (HULIS) formed from a lignin-type precursor in model cloud water, Geophys. Res. Lett., 31, L06115, doi:10.1029/2003GL018962.

Hoffer, A., A. Gelencser, P. Guyon, G. Kiss, O. Schnid, G. Frank, P. Artaxo, and M. Andreae (2006), Optical properties of humic-like substances (HULIS) in biomass-burning aerosols, Atmos. Chem. Phys., 6, 3563-3570, doi:10.5194/acp-6-3563-2006.

Jimenez, J. L., et al. (2009), Evolution of organic aerosols in the atmosphere, Science, 326, 1525-1529.

Jurányi, Z., et al. (2009), Influence of gas-to-particle partitioning on the hygroscopic and droplet activation behaviour of $\alpha$-pinene secondary organic aerosol, Phys. Chem. Chem. Phys., 11, 8091-8097, doi:10.1039/ b904162a.

Kalberer, M., et al. (2004), Identification of polymers as major components of atmospheric organic aerosols, Science, 303, 1659-1662, doi:10.1126/ science. 1092185

Kiselev, A., H. Wex, F. Stratmann, A. Nadeev, and D. Karpushenko (2005), White-light optical particle spectrometer for in-situ measurements of condensational growth of aerosol particles, Appl. Opt., 44, 4693-4701, doi:10.1364/AO.44.004693.

Kiss, G., B. Varga, I. Galambos, and I. Ganszky (2002), Characterization of water-soluble organic matter isolated from atmospheric fine aerosol, J. Geophys. Res., 107(D21), 8339, doi:10.1029/2001JD000603.

Kiss, G., E. Tombácz, and H.-C. Hansson (2005), Surface tension effects of humic-like substances in the aqueous extract of tropospheric fine aerosol, J. Aerosol Chem., 50, 279-294, doi:10.1007/s10874-005-5079-5.

Krivácsy, Z., et al. (2000), Study of humic-like substances in fog and interstitial aerosol by size-exclusion chromatography and capillary electrophoresis, Atmos. Environ., 34, 4273-4281, doi:10.1016/S1352-2310(00) 00211-9.

Krivácsy, Z., A. Hoffer, Zs. Sahrvari, D. Temesi, U. Baltensperger, S. Nyeki, E. Weingartner, S. Kleefeld, and S. G. Jennings (2001), Role of organic and black carbon in the chemical composition of atmospheric aerosol at European background sites, Atmos. Environ., 35, 6231-6244, doi:10.1016/S1352-2310(01)00467-8.

Krivácsy, Z., G. Kiss, D. Ceburnis, G. Jennings, W. Maenhaut, I. Salma, and D. Shooter (2008), Study of water-soluble atmospheric humic matter in urban and marine environments, Atmos. Res., 87, 1-12, doi:10.1016/ j.atmosres.2007.04.005.

Lammel, G., F. Schneider, E. Brüggemann, T. Gnauk, A. Röhrl, and P. Wieser (2004), Aerosols emitted from a livestock in Southern Germany, Water Air Soil Pollut., 154, 313-330, doi:10.1023/B: WATE.0000022962.65942.4b.

Limbeck, A., M. Handler, B. Neuberger, B. Klatzer, and H. Puxbaum (2005), Carbon-specific analysis of humic-like substances in atmospheric aerosol and precipitation samples, Anal. Chem., 77, 7288-7293, doi:10.1021/ac0509531.

Lin, P., G. Engling, and J. Z. Yu (2010a), Humic-like substances in fresh emissions of rice straw burning and in ambient aerosols in the Pearl river delta region, China, Atmos. Chem. Phys., 10, 6487-6500, doi:10.5194/ acp-10-6487-2010.

Lin, P., X. F. Huang, L. Y. He, and J. Z. Yu (2010b), Abundance and size distribution of HULIS in ambient aerosols at a rural site in South China, J. Aerosol Sci., 41, 74-87, doi:10.1016/j.jaerosci.2009.09.001.

Lowenthal, D. H., R. D. Borys, and M. A. Wetzel (2002), Aerosol distributions and cloud interactions at a mountaintop laboratory, J. Geophys. Res., 107(D18), 4345, doi:10.1029/2001JD002046.

Massling, A., J. K. Nøjgaard, T. Ellermann, M. Ketzel, and C. Nordstrøm (2011), Particle project 2008-2010. Particulate contribution from traffic in Copenhagen, Tech. Rep. 837, Natl. Environ. Res. Inst., Aarhus Univ., Aarhus, Denmark.

Mayol-Bracero, O. L., P. Guyon, B. Graham, G. Roberts, M. O. Andreae, S. Decesari, M. C. Facchini, S. Fuzzi, and P. Artaxo (2002), Biomass burning aerosols over Amazonia: 2. Apportionment of the chemical composition and importance of the polyacidic fraction, J. Geophys. Res., 107(D20), 8091, doi:10.1029/2001JD000522.

Medina, J., A. Nenes, R.-E. P. Sotiropoulou, L. D. Cottrell, L. D. Ziemba, P. J. Beckman, and R. J. Griffin (2007), Cloud condensation nuclei closure during the International Consortium for Atmospheric Research on Transport and Transformation 2004 campaign: Effects of size-resolved composition, J. Geophys. Res., 112, D10S31, doi:10.1029/2006JD007588.

Miller, J. N., and J. C. Miller (2010), Statistics and Chemometrics for Analytical Chemistry, 6th ed., Prentice Hall, New York.

Neusüss, C., M. Pelzing, A. Plewka, and H. Herrmann (2002), Carbonaceous aerosol over the Indian Ocean: $\mathrm{OC} / \mathrm{EC}$ fractions and selected specifications from size-segregated onboard samples, J. Geophys. Res., 107(D19), 8031, doi:10.1029/2001JD000327.

Obrist D., A. G. Hallar, I. McCubbin, B. B. Stephens, and T. Rahn (2008), Measurements of atmospheric mercury at Storm Peak Laboratory in the Rocky Mountains: Evidence for long-range transport from Asia, boundary layer contributions, and plant mercury uptake, Atmos. Environ., 42, 7579-7589, doi:10.1016/j.atmosenv.2008.06.051.

Peterson, M. R., and M. H. Richards (2002), Thermal-optical-transmittance analysis for organic, elemental, carbonate, total carbon and OCX2 in PM2.5 by the EPA/NIOSH method (Session 5, Paper 83), paper presented at Symposium on Air Quality Measurement Methods and Technology, Air and Waste Manage. Assoc., San Francisco, Calif.

Petters, M. D., and S. M. Kreidenweis (2007), A single parameter representation of hygroscopic growth and cloud condensation nucleus activity, Atmos. Chem. Phys., 7, 1961-1971, doi:10.5194/acp-7-1961-2007.

Petters, M. D., S. M. Kreidenweis, A. J. Prenni, R. C. Sullivan, C. M. Carrico, K. A. Koehler, and P. J. Ziemann (2009), Role of molecular size in cloud droplet activation, Geophys. Res. Lett., 36, L22801, doi:10.1029/2009GL040131.

Salma, I., R. Ocskaya, I. Varga, and W. Maenhaut (2006), Surface tension of atmospheric humic-like substances in connection with relaxation, dilution, and solution pH, J. Geophys. Res., 111, D23205, doi:10.1029/ 2005JD007015

Salma, I., R. Ocskaya, X. Chib, and W. Maenhaut (2007), Sampling artefacts, concentration and chemical composition of fine water-soluble organic carbon and humic-like substances in a continental urban atmospheric environment, Atmos. Environ., 41, 4106-4118, doi:10.1016/ j.atmosenv.2007.01.027

Salma, I., T. Mészáros, W. Maenhaut, E. Vass, and Z. Majer (2010), Chirality and the origin of atmospheric humic-like substances, Atmos. Chem. Phys., 10, 1315-1327, doi:10.5194/acp-10-1315-2010.

Samy S., L. R. Mazzoleni, S. Mishra, B. Zielinska, and A. G. Hallar (2010), Water-soluble organic compounds at a mountain-top site in Colorado, USA, Atmos. Environ., 44, 1663-1671, doi:10.1016/j.atmosenv.2010.01.033.

Shantz, N. C., W. R. Leaitch, L. Phinney, M. Mozurkewich, and D. ToomSauntry (2008), The effect of organic compounds on the growth rate of 
cloud droplets in marine and forest settings, Atmos. Chem. Phys., 8, 5869-5887, doi:10.5194/acp-8-5869-2008.

Song, J., L. He, P. Peng, J. Zhao, and S. Ma (2012), Chemical and isotopic composition of humic-like substances (HULIS) in ambient aerosols in Guangzhou, South China, Aerosol Sci. Technol., 46, 533-546, doi:10.1080/ 02786826.2011 .645956 .

Spindler, G., E. Brüggemann, T. Gnauk, A. Grüner, K. Müller, and H. Herrmann (2010), A four-year size-segregated characterization study of particles PM10, PM2.5 and PM1 depending on air mass origin at Melpitz, Atmos. Environ., 44, 164-173, doi:10.1016/j.atmosenv.2009. 10.015 .

Sullivan, R. C., M. J. K. Moore, M. D. Petters, S. M. Kreidenweis, G. C. Roberts, and K. A. Prather (2009), Effect of chemical mixing state on the hygroscopicity and cloud nucleation properties of calcium mineral dust particles, Atmos. Chem. Phys., 9, 3303-3316, doi:10.5194/acp-93303-2009.

Svenningsson, B., et al. (2006), Hygroscopic growth and critical supersaturations for mixed aerosol particles of inorganic and organic compounds of atmospheric relevance, Atmos. Chem. Phys., 6, 1937-1952, doi:10.5194/ acp-6-1937-2006

Taraniuk, I., E. R. Graber, A. Kostinski, and Y. Rudich (2007), Surfactant properties of atmospheric and model humic-like substances (HULIS), Geophys. Res. Lett., 34, L16807, doi:10.1029/2007GL029576.

Timonen, H., et al. (2012), Characteristics, sources and water-solubility of ambient submicron organic aerosol in spring time in Helsinki, Finland, J. Aerosol Sci., doi:10.1016/j.jaerosci.2012.06.005, in press.

Turpin, B. J. and H.-J. Lim (2001), Species contributions to PM2.5 mass concentrations: Revisiting common assumptions for estimating organic mass, Aerosol Sci. Technol., 35, 602-610, doi:10.1080/02786820119445. van Pinxteren, D., E. Brüggemann, T. Gnauk, Y. linuma, K. Müller, A. Nowak, P. Achtert, A. Wiedensohler, and H. Herrmann (2009), Sizeand time-resolved chemical particle characterization during CAREBeijing2006: Different pollution regimes and diurnal profiles, J. Geophys. Res., 114, D00G09, doi:10.1029/2008JD010890.

Varga, B., G. Kiss, I. Ganszky, A. Gelencsér, and Z. Krivácsy (2001), Isolation of water-soluble organic matter from atmospheric aerosol, Talanta, 55, 561-672, doi:10.1016/S0039-9140(01)00446-5.

Wex, H., T. Henning, I. Salma, R. Ocskay, A. Kiselev, S. Henning, A. Massling, A. Wiedensohler, and F. Stratmann (2007), Hygroscopic growth and measured and modeled critical super-saturations of an atmospheric HULIS sample, Geophys. Res. Lett., 34, L02818, doi:10.1029/ 2006GL028260.

Wex, H., M. D. Petters, C. M. Carrico, E. Hallbauer, A. Massling, G. R. McMeeking, L. Poulain, Z. Wu, S. M. Kreidenweis, and F. Stratmann (2009), Towards closing the gap between hygroscopic growth and activation for secondary organic aerosol: Part 1-Evidence from measurements, Atmos. Chem. Phys., 9, 3987-3997, doi:10.5194/acp-9-3987-2009.

Wexler, A. S., and S. L. Clegg (2002), Atmospheric aerosol models for systems including the ions $\mathrm{H}^{+}, \mathrm{NH}_{4}^{+}, \mathrm{Na}^{+}, \mathrm{SO}_{4}^{2-}, \mathrm{NO}_{3}^{-}, \mathrm{Cl}^{-}, \mathrm{Br}^{-}$, and $\mathrm{H}_{2} \mathrm{O}$, J. Geophys. Res., 107(D14), 4207, doi:10.1029/2001JD000451

Yu, L. E., M. L. Shulman, R. Kopperud, and L. M. Hildemann (2005), Fine organic aerosols collected in a humid, rural location (Great Smoky Mountains, Tennessee, USA): Chemical and temporal characteristics, Atmos. Environ., 39, 6037-6050, doi:10.1016/j.atmosenv.2005.06.043.

Ziese, M., H. Wex, E. Nilsson, I. Salma, R. Ocskay, T. Henning, A. Massling, and F. Stratmann (2008), Hygroscopic growth and activation of HULIS particles: Experimental data and a new iterative parameterization scheme for complex aerosol particles, Atmos. Chem. Phys., 8, 1855-1866, doi:10.5194/acp-8-1855-2008. 